\title{
Engineering geology for weak rocks of Abu Hamour surface and ground water drainage tunnel phase-1 Doha, Qatar
}

\author{
JB Stypulkowski, AK Pathak, FG Bernardeau \\ CDM Smith Inc. \\ Doha Qatar \\ stypulkowskijb@cdmsmith.com
}

\begin{abstract}
This paper discusses results of analysis from geotechnical database collected during field mapping of shafts in weak/soft rocks of Abu Hamour tunnel project area of South Doha, Qatar. Shafts are connected to the main tunnel by short tunnels - adits, excavated using sequential excavation method. Shaft and adit excavation was carried out by excavators while tunnels were TBM mined. A comprehensive geotechnical data collection system in weak/soft rocks has been created and successfully implemented. It involved geological mapping of 25 shafts and relogging of 18 boreholes drilled at shaft locations. The authors correlated common classification systems: $Q$ and RMR from 3 phases of design/construction: original assessment using boring logs from contract documents, relogging of the core available from the same borings and shaft mapping. Original assessment when compared with shaft mapping results has been generally conservative. Mapping results when compared with re-logging of the available shaft borings were generally optimistic. When mapping results were compared with re-logging effort in $72 \%$ - RMR, 61\%-Q, results were similar. In 18\%-RMR, 22\%-Q mapping turned up more optimistic than re-logging and only about $10 \%$-RMR, $18 \%-Q$ largely for near the surface results, mapping showed worst rock that otherwise would have been predicted. The project involved construction dewatering, by deep wells or/and multiple soil treatment using injection (grouting) techniques as methods of water control during construction in the shafts and adits. Some locations required more effort to control the water inflow than others. The correlations with observed rock mass conditions to increased dewatering and injection efforts are presented. It is the first TBM tunnel project in Qatar. Civil works has been largely completed while the project is scheduled for delivery by January 2017.
\end{abstract}

Keywords-weak/soft rocks; EPB TBM; deep shafts; Q; RM; geological mapping.

\section{INTRODUCTION}

Abu Hamour (Musaimeer) Surface \& Ground Water Drainage Tunnel - Phase I (AHSO) is 9.5km long with $3.7 \mathrm{~m}$ ID storm water tunnel. Tunnel depth is about $30 \mathrm{~m}$ and the shafts are up to $31 \mathrm{~m}$ deep, sized from $5.4 \mathrm{~m}$ to $11.5 \mathrm{~m}$ finished ID. Final liner thickness vary from 300 to $600 \mathrm{~mm}$. Shafts are connected to the main tunnel by mechanically excavated short tunnel adits. Shaft and adit excavation was carried out by excavators, tunnels were mined by two TBMs running in opposite directions from shaft located in the middle of the tunnel alignment and nine micro tunnels were driven by MTBM. Steel fiber reinforced concrete segments were used for tunnel support, steel reinforced concrete for shaft support and steel reinforced concrete pipes for micro tunnels. The Owner (or Employer), ASHGHAL/PWA, is the designated Engineer, who is represented by the Engineer's Representative CDM Smith Inc. CDM Smith Inc. engineering team provides design review, verification and approval for all the design produced by the Contractor's team. CDM Smith Inc. is also the Construction Manager on this project.

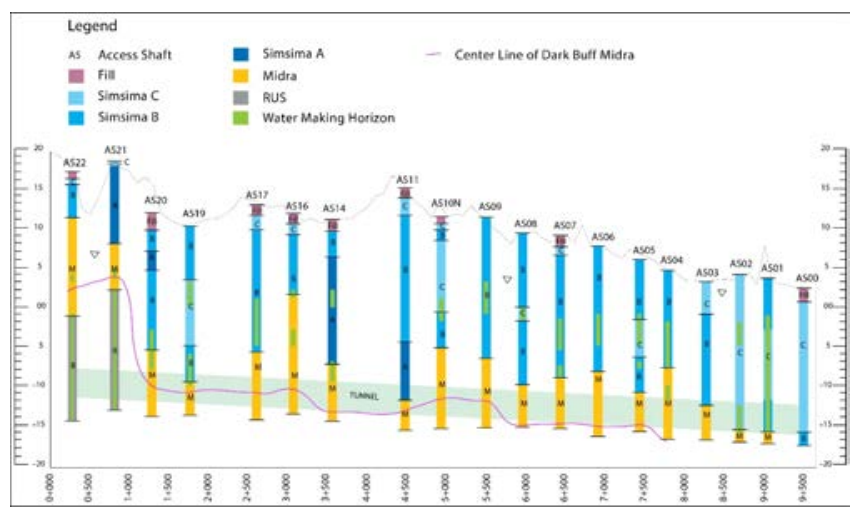

Fig. 1.Subsurface Tunnel Profile along Tunnel Alignment

\section{Project OVERVIEW}

Integral to Phase I of the project, are 19 access shafts (AS) located at about $500 \mathrm{~m}$ on center. Some of these shafts are drop shafts that facilitate runoff inflows along the route of the tunnel. Offline shafts used sequential excavation tunneling methods to connect to tunnel in 15 locations. The tunnel runs from an existing access shaft AS23 to a retrieving shaft located within footprint of a future pumping station at the coastline to be constructed under Phase II of the project. There are also 3 online shafts, 1 existing shaft and 6 additional branch shafts (which are terminal shafts 
facilitating connections to main tunnel and were accomplished by microtunneling). Access Shaft AS11 a launching shaft $32 \mathrm{~m}$ in length, $10 \mathrm{~m}$ wide and $31 \mathrm{~m}$ deep. Its central position along the alignment, facilitated mining in opposite directions and provided access for tunnel construction for the duration of the project. After completion of construction a smaller $5.4 \mathrm{~m}$ diameter permanent shaft will be constructed within the temporary shaft and the excess space around it backfilled. Two other shafts of $10 \mathrm{~m}$ diameter were intended as TBM reception shafts at each end of the project: AS22R and PS-TBM recovery shaft east, located inside future pump station footprint.

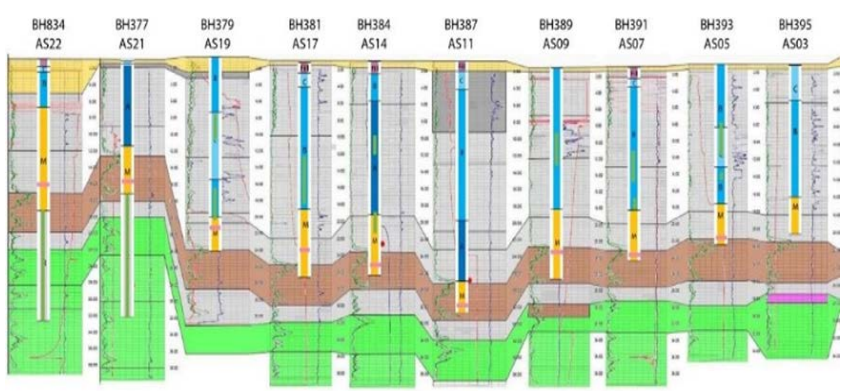

Fig. 2. Geophysical Log Interpretative Correlation with Results of Shaft Mapping

\section{REGIONAL GEOLOGY}

Area is geologically a part of the Arabian Gulf Basin. It forms a part of the Arabian shelf between the Arabian shield and Iranian mobile belt. Thickness of sediments in the Qatar region is estimated to be about $10 \mathrm{~km}$. The post Cretaceous sedimentation is basically a sequence of shallow marine limestone with occasional shale in a shallow basin. The formations encountered in Doha region comprise of Quaternary marine, aeolian and sabkha deposits. They are: Rus of Lower Eocene, Lower Dammam and Upper Dammam of Middle Eocene and Lower Dam of Lower Miocene. We encountered following rock domains listed from ground surface down shown in (Fig. 1). Simsima Limestone (represented by 3 shades of blue on Fig. 1. which contains Dolomite of Upper Dammam formation, Midra Shale (yellow) of Lower Dammam formation and Rus (grey) of Lower Eocene. Water making horizons are marked in green on (Fig. 1).

\section{GEOLOGY EnCOUNTERED}

In the literature, as common approach dictates, the Dammam formation is divided into following main stratigraphic units: Simsima, Midra, and Rus. Based on findings in the shafts we reinterpreted Simsima further and sub divided it into Simsima A, Simsima B and Simsima C based on its strength. Simsima $\mathrm{C}$ is typically fine to medium grained dolomitic limestone, loosely compacted highly weathered, extremely weak to very weak heterogeneous mix of boulders and matrix. It has been observed that compaction and strength increases with depth when transgress into Simsima B which is moderately weathered, weak to medium strong. The composition is same as
Simsima C. With further increase in depth the grade of compaction increases and the ground mass becomes strong to very strong and becomes Simsima A Transition from Simsima to Midra is marked by layers of gypsum. Midra was encountered at different elevations along the alignment. Visually the most distinguishing feature between Simsima and Midra was the change in color however there is also gradational change: Simsima is sandy-silty, whereas Midra is silty-clayey. Based on shaft mapping we reinterpreted and further subdivided Midra into two categories which we called Light Buff Midra overlying Dark Buff Midra. They are compositionally, structurally and strength wise different from each other with sharp contacts. Below the Midra Unit is formation. Rus is characterized by the presence of horizontal layers with different color, composition, grain size, weathering and strength. Shale, dolomitic limestone, pinkish dolomitic limestone, green clay, marl, clay stone, gypsum constitute the main rock mass.

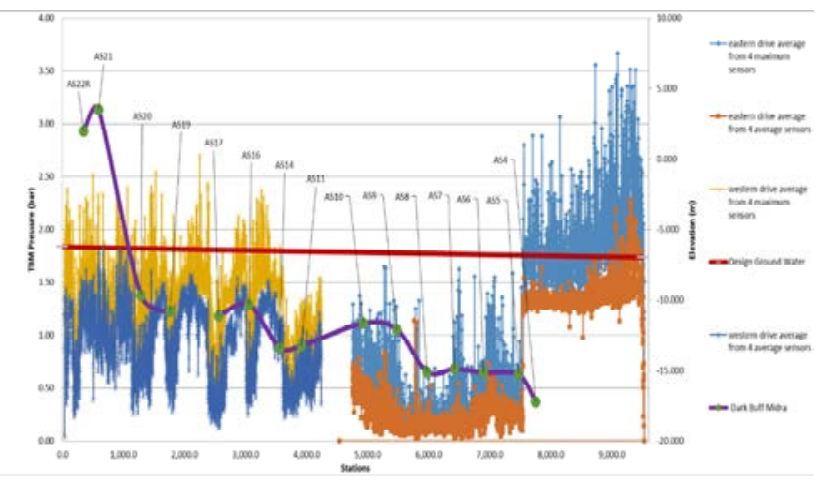

Fig. 3. Pressures recorded during tunneling compared to design

Thickness of layers varies from $2 \mathrm{~cm}$ to $1.5 \mathrm{~m}$. Strength varies from medium strong to weak and very weak rock to extremely weak rock. The silty/sandy limestone is only $34 \%$ while clay rich components are $66 \%$ at the tunneling horizon at the shaft junctions. The characteristics of the ground mass along the alignment vary significantly both horizontally and vertically over a small distance. Amount of primary crystalline rock and secondary materials like silt, gypsum, chert and attapulgite clay are the reason. Variations are also governed by the extent of digenetic processes, cementation of boulders and matrix, fractures, secondary materials karstification and weathering. The test results from X-ray diffraction yielded around AS22R: Dolomite (82-95\%), Palygorskite $<9 \%$ except at one horizon where it is $91 \%$, Calcite $<9 \%$, Gypsum $<7 \%$, Quartz $<7 \%$ and Polyhalite $<7 \%$. For detailed geology description and mapping results[12].

The complete geological profile along the tunnel alignment as mapped is on Fig. 1. Steep slope in Dark Buff Midra between AS21 and AS22 is noted and may be due to a graben type of structure which is reflected by the topography. It may represent a doline type of structure resulting from the collapse of an evaporate horizon in the lower Rus formation at a greater depth (as per contractor's designer). 


\section{INTACT ROCK PROPERTIES}

Laboratory tests were conducted on rock samples obtained from borings before construction. Uniaxial compressive strength (UCS) test results range between 2 $65 \mathrm{MPa}$ (median 15MPa). Tensile strength from Brazilian tests range between $0.1-9.1 \mathrm{MPa}$ (median 1.7MPa). point load testing Is(50) ranges between $0.03-7.5 \mathrm{MPa}$ (median $1.3 \mathrm{MPa}$ ). Young's modulus from UCS testing range between 0.4 and $49 \mathrm{GPa}$ (median 4.2GPa), from pressuremeter testing in initial loading range $79-5,310 \mathrm{MPa}$ (median 389MPa) while down-hole seismic test results range is $1-4.3 \mathrm{GPa}$ (median 2.4GPa). For additional details[12].

\section{GEOPHYSICAL LOGGING}

The colored image in the background of the Fig.2. was produced by geophysical survey during initial geotechnical investigations. Overlain on the image are the actual mapping results after excavation. We can see that while they are not matching it gives some indication about presence of different lithological horizons. Prediction of water making horizons (not shown) has not been consistent with observations made in the field as well.

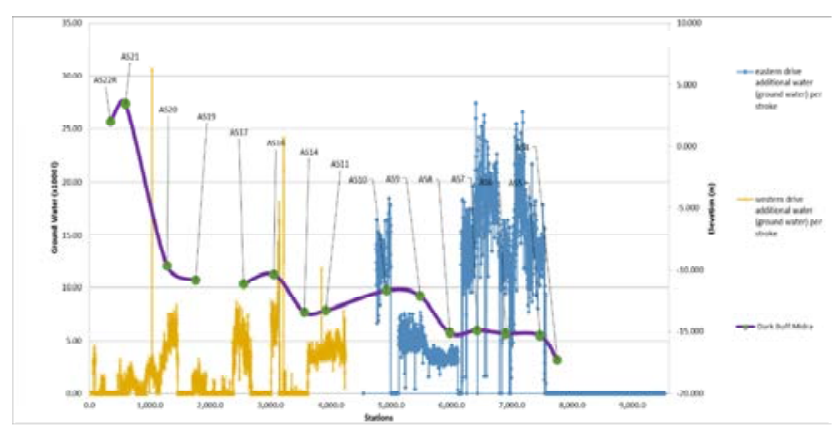

Fig. 4. Ground water pumped into chambers correlated with confining aquifer - Dark Buff Midra

\section{PERMEABILITY OF ROCK MASS}

The hydrogeology has been described in detail in [12]. As it appears from the (Fig.3), water pressures recorded during tunneling didn't reach anticipated level until station $\sim 7,500$ which is about $2 \mathrm{~km}$ from the sea. The Midra Shale Series which divides the two aquifers is indeed an aquitard between the two aquifers. The close relationship between the piezometric levels recorded in the boreholes (leading to erroneous design water level) suggests that two aquifers were likely breached in piezometer locations and led to incorrect water pressure estimates.

Significant quantities of the ground water (in addition to service water used for mixing conditioners) was added during tunneling until breaching confining aquifer Dark Buff Midra about $2 \mathrm{~km}$ before the shoreline as shown on (Fig. 4). It was determined as well that there are no correlations with increasing limestone content at the tunneling horizon when compared with the requirements for additional water (Fig. 5). Groundwater permeabilities were largely controlled by presence of connected solution cavities not the permeability of the matrix.

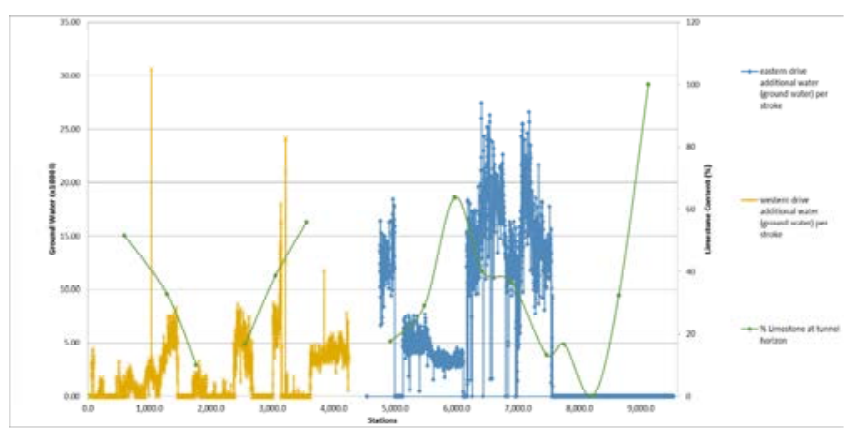

Fig.5. Additional groundwater added to TBMs during tunneling compared with limestone content at tunnel horizon

\section{VIII.TBM JACKING LOADS}

Since TBM jacking loads have been recorded during mining an attempt has been made to see if variation of the loads in different groups can be used to detect changing geology. Since bedded layers have varying strength an attempt to overcome harder layer could have changed balance of loading. During tunneling the advance cylinders were recorded for 4 groups as shown on (Fig. 6).

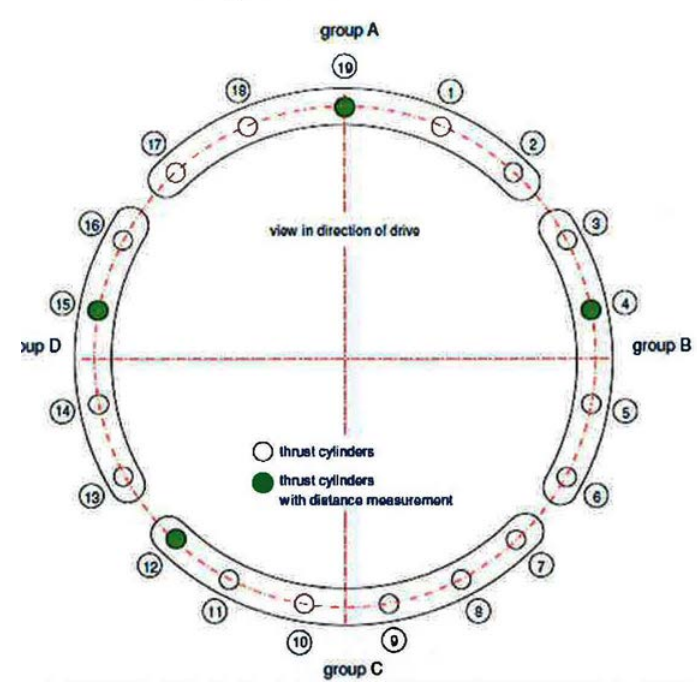

Fig.6. Layout of advance cylinders in TBMs with green dots indicated measured location

Jacking force group C - invert - was consistently higher than other three for both drives. Group A was $29 \%$ \& $41 \%$ of the Group C for western \& eastern drives respectively. Group C was smaller than Group D \& B only in the few cases. Only at the selected locations along alignment group A was consistently larger than group $\mathrm{C}$ as shown on the (Fig.7).

Concentration of jacking load at the crown was observed between AS16 and AS17 where ground mass at the tunneling horizon was the Light Buff Midra (LBM) and Dark Buff Midra (DBM) with clay component $72 \%$ and 
82\%. When comparing LBM/DBM thicknesses with TBM diameter it is clear that in this section of tunneling more than half of the face was in clay like material. The increase in jacking load at the crown when comparing with invert might be attributed to this condition. The same was also observed between AS19/AS20 and between AS03/AS04 but to lesser extent. Clay component was from $84 \%$ in AS19 to $66 \%$ in AS20 and from 64\% in AS3 to $80 \%$ in AS4.

\section{GENERAL OBSERVATIONS DURING SHAFT EXCAVATION}

All three stratigraphic units were encountered only in AS21 and AS22R, the western most shafts located about 9.5 $\mathrm{km}$ from the shoreline. All other shafts were excavated in Simsima and Midra except PS - eastern TBM retrieval shaft which was in Simsima only. Over all stratigraphy slopes down towards the sea. Entire ground mass is classified as soft/weak rock despite occasional horizons of hard rock (chert and Simsima A). Karstification was not extensive. It was limited to solution cavities up to a certain depth mainly localized in Simsima. The maximum size of open solution cavity was $10 \mathrm{~m}$ long and $1 \mathrm{~m}$ height/open depth could not be assessed (AS10) however average size of the solution cavities were in $10-20 \mathrm{~cm}$ range. Limited karstification is due to Simsima mineralogy: Dolomitic Limestone. Dolomite is the major component and is not as susceptible to water action. It is possible that the rock masses are of tertiary formations and did not have enough time for extensive karstification to develop in a desert climate with limited water availability.

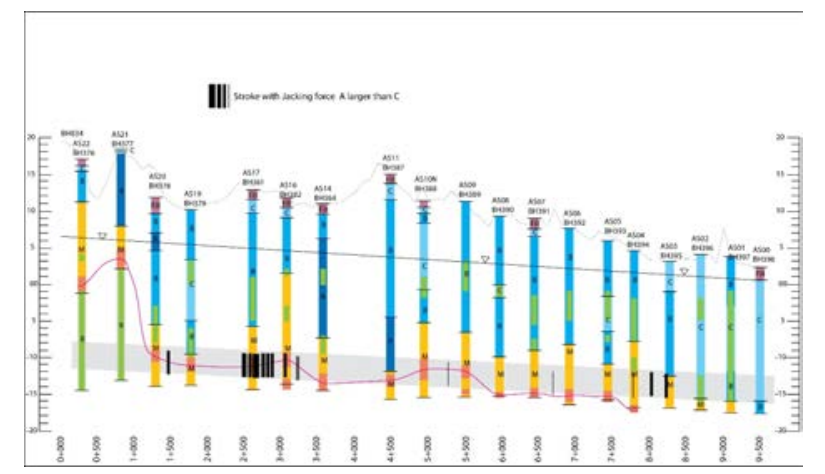

Fig. 7. Occurrence of jacking force in invert being smaller than in the crown along the alignment

In all the shafts flowing conditions were encountered and groundwater was commonly coming through open solution cavities in Simsima between elevations 0m to $10 \mathrm{~m}$. Some of the contacts between Simsima and Midra were flowing. Below level $-10 \mathrm{~m}$ the clay rich Midra layer is less soluble to water and acts as aquitard and separates the aquifers. There were some limestone beds within Midra and Rus which bleed water at slow rate which in time saturated all beds lying below. About $67 \%$ of all excavation was either in water bearing horizons or below them. Flow meter testing in boreholes was carried out during geotechnical investigation prior to the initiation of the project and no ground water flow was observed. Observations made during excavation indicated that water drained in the shaft circumferentially

\section{GeOlogical aspects of excavation}

Chert (micro crystalline silica) is the hardest rock in the region. It was encountered in access shafts: AS14, AS19 and AS22R and found dipping towards east 10-15 degrees. In AS14 and AS19 it occurred in bands $15-25 \mathrm{~cm}$ thick usually fractured and did not impact excavation rate. However, in AS22R it formed a $40 \mathrm{~cm}$ thick contact between two stratigraphic units and $70-80 \mathrm{~cm}$ thick continuous bed in Rus formation was found at greater depth, resulting in decreased excavation rate for the shaft. Simsima A is a strong rock mass and was difficult to excavate and was encountered in shafts AS14, AS17S1, AS20 and AS21.

There were problems due to flowing condition in most of the shafts except the TBM launch shaft in the center of the alignment (AS11) and PS. The cut-off wall was constructed using hydro mill around the entire proposed pump station footprint including PS to a depth of $36 \mathrm{~m}$. It was successful in preventing water inflow in the shaft during excavation. PS is about $60 \mathrm{~m}$ from sea coast in mostly loosely compacted and high porosity ground mass. It should be pointed that a free flowing condition was encountered about 500 meters away from AS11 in shaft AS13. Numerous attempts to control the water failed and it was used as a discharge facility until it was abandoned and deleted from the scope. Water discharged into AS13 from other shafts caused flooding a few times due to excessive discharge flows and siltation in the bottom of the shaft. However, water level in that shaft remained stable most of the time. It is not clear at this time if capacity of the reservoir was ever exceeded.

Originally AS1 was a medium size shaft with $5.4 \mathrm{~m}$ finished ID. Later its purpose was changed and was redesigned to $8.5 \mathrm{~m}$ ID. The decision was made after casting of capping beam and installation of dewatering wells placing them inside the shaft. The tunnel alignment was also changed to make this shaft in line with the main tunnel. Bulkhead, on downstream tunnel will stop water inside the tunnel and provide access for inspection and maintenance of pump station in the future.

In AS14 in abandoned piezometer hole in the center of the shaft experienced water flowing at high pressure resulting in long delays and multiple injection attempts.

\section{GROUNDWATER EXTRACTION}

It has been concluded that occurrence of ground water is hard to predict both vertically and horizontally. Extreme variations were observed within small distances. To provide dry condition for excavation two wells deeper than the shafts were installed at each small diameter shaft, 3 in AS17, 4 in AS22shafts and AS11 had 6 installed. Pumps installed into these wells were continuously discharging out water acting like sumps. It was effective but not sufficient in most of the cases resulting in injection of Ordinary Portland Cement (OPC) grout. Since dewatering was largely 
unsuccessful grouting in combination with sumps was used to provide manageable excavation conditions.

\section{INJECTIONS TO LIMIT WATER FLOW}

Pre consolidation by injection using OPC grout was carried out to reduce the flow of water in most of the shafts. No other grouting materials were considered. Only 8 out of 25 didn't require any pre consolidation. Grouting from the surface involved drilling and injecting vertical holes around the periphery of the shaft with OPC mix. Horizontal holes were also drilled from within six shafts and OPC grout was injected in water making horizons. Applying combination of these methods as required were successful in reducing the flow to acceptable levels in all cases. It was concluded that flowing condition in the project area was caused mainly by the solution cavities. During excavation OPC grout was observed filling solution cavities only, there were no other lateral penetration noted, not even at the geological contacts. Effectiveness of the injecting OPC with one packer at the top was limited to solution cavities. In some of the shafts single injection of OPC grout was not successful in reducing the flow and it had to be repeated several times.

Additional injections of OPC as well as polyurethane (PU)/acrylic resin (AR) were required at the adits. About $80 \%$ of the adits required injection of OPC grout after final liner was installed. It was followed in $67 \%$ of the cases with acrylic resin (Mapegel UTT System2) injection followed again by Polyurethane Grout (Purinject 1C 115 ECO).

\section{INJECTIONS TO LIMIT LEAKING OF WATERPROOFING}

Upon shutting down the dewatering pumps after completion of the permanent support water seepage through the permanent support was noted in 7 out of 25 shafts. It happened despite the synthetic waterproofing membrane (2mm PVC) was installed in all the shafts. Seepage through the permanent support was successfully eliminated with injection of PU/AR. Five shafts had acrylic resin/polyurethane injected in east and two in west. Eight adits had OPC grout injected in the east while three in the west as well. In east side most of the excavation was in silty sandy Dolomitic Limestone while in west clay rich component was higher leading to the conclusion that overall rockmass permeability contributed to watertightness of the structures.

\section{XIV.NOTES ON TEMPORARY SUPPORTS IN SHAFTS}

Approach to temporary supports evolved in time during project duration. First shaft received the heaviest support due to high risk associated with TBM operations. It performed very well with limited measured deformations. Rest of the shafts below top $6 \mathrm{~m}$ were supposed to receive only wire mesh protection from rock falls. In fact, only in $24 \%$ of the shafts it was sufficient, in the rest $100 \mathrm{~mm}$ shotcrete was applied all the way to the invert. In addition, three more received additional shotcrete applications, often combined with wire mesh (AS22, AS10 \& AS1). All three of those shafts were large diameter shafts. In absence of water stand up time was very good. Weak rocks received multiple injections of OPC grout and shotcrete treatments as needed to provide resistance to injection pressures. Often flowing water through the solution cavities didn't cause stability problems influencing construction activities. The contractor's solution to limit "rain" in the shaft was to wrap it with plastic sheeting and channel water to sumps and dewatering wells for pumping. Waterproofing was installed over that sheeting. Except two instances where failure has occurred it worked well.

The authors correlated common classification systems: $\mathrm{Q}$ and RMR from 3 phases of design/construction: original assessment using boring logs from contract documents, relogging of the core available from the same borings and shaft mapping[12]. Original assessment when compared with shaft mapping results has been generally conservative. Mapping results when compared with re-logging of the available shaft borings were generally optimistic. When mapping results were compared with re-logging effort in $72 \%$ - RMR, 61\%-Q, results were similar. In 18\%-RMR, $22 \%-\mathrm{Q}$ mapping turned up more optimistic than re-logging and only about $10 \%-\mathrm{RMR}, 18 \%-\mathrm{Q}$ largely for near the surface results, mapping showed worst rock that otherwise would have been predicted.

A major shotcrete and rock mass failure occurred below water table in shaft AS01 between elevations -7 to -12m (lift $5 \mathrm{~m}$ ). Mapped Qw (max) in that area was between 0.92 and 0.66 which places it in support category 1 (Fig. 8). Support installed was wire mesh and shotcrete. The repair work was carried out using rock bolts, wire mesh and shotcrete. Total 51 rock bolts were installed (46 - 3m long and 5 - 5m long),

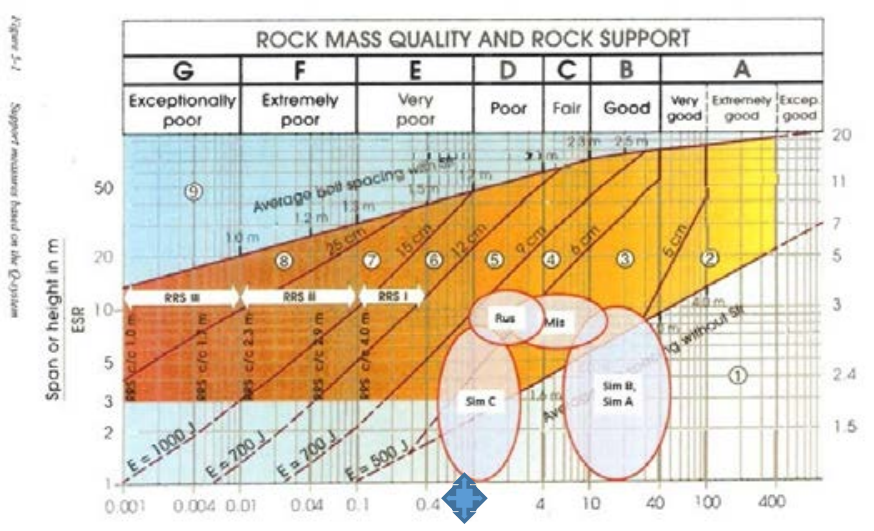

Fig. 8. Expected rock mass and support requirements in shafts as per $Q$ (Photo by NGI) Note callout inside Sim C for AS01 Q=0.9

with minimum of $300 \mathrm{~mm}$ of shotcrete. Drainage holes and high capacity dewatering pumps were successful in stabilizing excavation. The likely cause of failure was inadequate temporary support for this ground water rich rock mass. Horizontal injection of OPC grout was required 4 times in this location to control flow of water. From our experience at this shaft it could be concluded that NGI-Q system has limited applicability outside of boundaries suggested by [13]. 


\section{EXCAVATION CONSIDERATIONS}

Average excavation rate of the eastern shafts from AS10 to PS was marginally higher when compared with the rate for western shafts. Rock mass in eastern shafts was weaker despite contractor experiencing more water related problems in east. It can be therefore concluded that strength of rock mass strongly influenced rate of excavation. Excavation rate for rock masses with increasing strength was observed to reduce steeply. Excavation rate for clay rich formation Midra was close to the project average. There were multiple mixed rock masses in the transition zones between siltysandy dolomitic limestone and clay rich formations with slightly varying excavation rates.

There were 16 shafts with permanent diameter of $5.4 \mathrm{~m}$ which reported excavation rate very similar to 9 shafts with diameters: $8.5 \mathrm{~m}, 10 \mathrm{~m}$ and $11.5 \mathrm{~m}$. Size difference of shafts did not have much effect on the excavation rate despite larger size enabled use of two excavators operating simultaneously. This indicates that efficiency of the mucking operation contributed to the lower than expected excavation rate. Excavation rate (mean) above the water table when compared with below the water table shows almost 50\% higher. Maximum excavation rate was achieved in PS shaft in Simsima C with nominal water inflows. The lowest excavation rate was in AS10N (11.5m dia.) large diameter shaft. Excavation in all the shafts were done by excavators using hoe rams of different makes and sizes. Excavator used were as follows: Dosan 210WV, CAT 320 D, Mini Excavator-Yammer Vic55, Mini ExcavatorHyundai Robex 55-7, Mini Excavator- Hyundai Robex 6095, JCB 3CX.

\section{XVI.CONCLUSIONS}

The writers created comprehensive geotechnical data collection system on the tunneling project in weak/soft rocks which has been successfully implemented. The database was compared with TBM performance data and projected back to the geology. The observations made are presented herein. Groundwater permeabilities were largely controlled by presence of connected solution cavities not the permeability of the matrix and they are very hard to predict. Interpreted TBM behavior pointed correctly to clay rich tunneling horizons. Temporary support application in shafts in $76 \%$ required use of shotcrete protective layer. Since the weak/soft rocks turn into soil after excavation it has been concluded that GSI approach has limited applicability and should not be used alone in development of input parameters for numerical analysis. From our experience at AS1 failure it could be concluded that NGI-Q system has limited applicability outside of boundaries[13]. Strength of rock mass strongly influenced rate of excavation and excavation rates above water table were double of the ones below.

\section{ACKNOWLEDGEMENT}

The writers acknowledge Salini-Impregilo S.p.A who are successfully excavating the shafts and tunnels.

\section{REFERENCES}

[1] Abu Zeid, M.M., "Lithostratigraphy and framework of sedimentation of the subsurface Paleogene succession in northern Qatar", Arabian Gulf. N.Jb. Geol. Paliaiont. Mh.:191-204, 1991.

[2] Bieniawski, Z.T, "Engineering classification of jointed rock masses", Trans. S.Afr. Inst. Civ.Eng.15, 335-344, 1973..

[3] Bieniawski, Z.T, "The geomechanics classification rock engineering applications", Proc. 4th Int. Congr. Rock. Mech., ISRM, Montreux, Vol. 2, 41-48, 1979.

[4] Bieniawski, Z.T, "Engineering rock mass classification", Jhon Wiley \& Sons. New York, pp. 272, 1989.

[5] Bieniawski, Z.T, "Engineering rock mass classifications", New York: John Wiley \& Sons. pp. 251, 1989.

[6] Geotechnical Interpretative Report, SALINI-IMPREGILO. S.P.A, 14/11/2013.

[7] Handbook- "Using the Q-System Rock mass classification and support design", NGI, 2013, www.ngi.no (Author name required).

[8] Jafari, M.R., Bernardeau, F.G., Stypulkowski, J.B., Siyam, A.F.M., "Abu Hamour Outfall Tunnel Project In Doha, Qatar”, in RETC Rapid Excavation \& Tunneling Conference and Exhibit, June 7 - 10, 2015, New Orleans, LA, pp $401-411$

[9] LeBlanc, J., "A Fossil Hunting Guide to the Tertiary Formations of Qatar, Middle East", First Edition, March 2008.

[10] Marinos, V., Marinos, P. \& Hoek, "The geological strength index: applications and limitations", E. Bull Eng Geol Environ, 64:55, 2005.

[11] Palicki, K. S., "A graphical method for the classification of rock and weak rock masses based on field observations", Engineering Environmental Geoscience, Vol. 3, No. 1, pp. 7-12, 1997.

[12] Pathak, A.K., Stypulkowski, J.B, Bernardeau, F.G., "Supervision of Engineering Geological Activities during Construction of Abu Hamour Surface and Ground Water Drainage Tunnel Phase-1 Doha, Qatar", in International Conference on Engineering Geology in New Millennium at IIT, New Delhi 27-29. Special Publication, J of EG pp 467-486, Oct 2015

[13] Palmstrom, A., Broch, E., "Use and misuse of rock mass classification systems withparticular reference to the Q-system", Tunnelling and Underground Space Technology 21, 575-593, 2006.

[14] Stypulkowski, J. B., Siyam, A. A. F. M., Bernardeau, F. G. and Al Kuwari, N. G., “Abu Hamour Drainage Tunnel, First TBM Mined Tunnel in Doha, Qatar”. The First Arabian Tunnelling Conference \& Exhibition, Dubai, pp. 300-314, 2013.

[15] Stypulkowski, J.B., Pathak, A.K., Bernardeau, F.G.,” Abu Hamour, TBM Launch Shaft, "A Rock Mass Classification Attempt for a Deep Shaft in Doha, Qatar." in EUROCK14, ISRM International Symposium, May 27 - 29, Vigo, Spain, CRC Press, Taylor \& Francis Group, pp 117, 2014.

[16] Siyam, A.F.M., Bernardeau, F.G., "Structural and Construction Challenges for Shafts on Abu Hamour Surface \& Groundwater Drainage Tunnel” Arabian Tunnelling Conference and Exhibition, Dubai, UAE, 23-25th November 2015,

[17] Siyam, A.F.M., Stypulkowski, J.B., Bernardeau, F.G., "Improvement to Longevity of Tunnels in Aggressive Ground Conditions in the Middle East”, Arabian Tunnelling Conference and Exhibition Abu Dhabi, UAE, pp 163-185, 9-10th December 2014,

[18] Terzaghi, K., "Rock defects and loads on tunnel supports. Rock Tunnelling with Steel Supports", Ed. R.V. Proctor and T. White, Commercial Shearing Co.Younstown, OH, 15-19, 1946.

[19] @Risk, Palisade Corporation, 31 Decker Road, Newfield, NY 14887. 